\title{
Modelo Principal-Agente para contratos entre pequenos produtores e empresa exportadora de manga no Rio Grande do Norte
}

\author{
Luciano Menezes Bezerra Sampaio*
}

Resumo: A fruticultura é uma atividade de grande importância na balança comercial brasileira e mais ainda para a região Nordeste. As diversas exigências do mercado exportador de frutas, como os certificados de qualidade, aliadas aos entraves internos da produção e da comercialização, entre os quais a ausência de padronização dos produtos e a falta de crédito, fizeram da intermediação das exportações uma prática regular. Grandes empresas, cooperativas, associações e ONG's recebem as produções de muitos pequenos produtores e as exportam, conjuntamente com sua própria produção, quando também produzem. No Nordeste, é comum o agente exportador oferecer contratos de exportação aos produtores que incluem assistência técnica, administrativa e jurídica e os insumos necessários à produção. Este trabalho formula uma proposta de modelagem, usando a teoria dos jogos, mais especificamente a abordagem Principal-Agente, para os contratos de exportação entre produtores e exportadores da fruticultura. Aplicou-se a proposta para os pequenos produtores de manga do Rio Grande do Norte, e mostrou-se que a escolha do tipo de contrato da maioria dos produtores é ótima para ambas as partes e que estes contratos incentivam o produtor a aplicar esforço

*Professor Adjunto, Departamento e Pós-Graduação de Economia da Universidade Federal da Paraíba. Doutor em economia pelo Pimes - UFPE/Sorbonne (Paris 1). luciano.sampaio@pesquisador.cnpq.br

$\mathrm{O}$ autor agradece o apoio do $\mathrm{CNPq}$ pelo financiamento do projeto que resultou este artigo. 
880 - Modelo Principal-Agente para contratos entre pequenos produtores e empresa exportadora de manga no Rio Grande do Norte

elevado na produção. Extensões da modelagem proposta podem incluir barganha nas negociações ou considerar um modelo de jogo dinâmico.

Palavras-chave: teoria dos jogos, pequeno produtor, fruticultura irrigada, exportações.

Classificação JEL: Q10, Q12, D86

Abstract: Fruit production is an activity of great importance in the Brazilian commercial balance and even more in the Northeastern region. Intermediation is a regular practice in the fruit exporting market due to existence of requirements, such as quality certificates, and of internal problems in production and commercialization, such as credit limitations and absence of product standardization. Large companies, cooperatives, associations and NGOs receive products from many small producers and export them together with their own products. In Northeast, it is common that the exporting agent offers contracts to producers that include technical, administrative and legal assistance plus input supply. This paper proposes a model, using the principal-agent approach of game theory, to the case of contracts between mango exporting agents and small producers, in Rio Grande do Norte. The contract type chosen by most of the producers is optimal for both parts and leads producers to apply a high level of effort in their production. However, in the long run, these contracts may be changed with strong impact on the small producers. Extensions of the model can include bargaining in the negotiations or temporal changes, moving from static to dynamic game cases.

Key-words: game theory, small producers, irrigated fruit production, exportation

JEL Classification: Q10, Q12, D86

\section{Introdução}

A fruticultura é uma atividade de grande importância na balança comercial brasileira e mais ainda para a região Nordeste. Entre os produtos 
da região, destacam-se, no Ceará, a castanha de caju; no Vale do São Francisco, entre Pernambuco e Bahia, banana, uva e manga; na Paraíba, abacaxi e mamão; e no Rio Grande do Norte (RN), melão, banana, castanha e, mais recentemente, manga. Neste último estado, a fruticultura responde por aproximadamente $18 \%$ das exportações (MDIC, 2006).

Os estudos de cadeias produtivas e arranjos produtivos locais, financiados pelo Sebrae, Banco do Nordeste, governos de estados, e outras instituições, apontam quase que unanimemente, a ausência de padronização dos produtos e a falta de crédito como principais entraves para a comercialização da produção pelo pequeno produtor. Para exportação, com normas ainda mais rigorosas que para o mercado interno, e ainda devido ao fator escala, as dificuldades de comercialização direta entre pequeno produtor e atacado e/ ou varejo internacional são ainda maiores (Lacerda e Lacerda, 2004; Pimentel et al., 2000; Paulo Pessoa et al., 2000, entre outros).

Assim, a intermediação é prática corrente na comercialização de frutas para exportação em todos os estados da região Nordeste, associada à concentração das exportações em poucos agentes, caracterizando-se um oligopólio ou até mesmo um monopólio exportador. Os exportadores (grandes empresas, cooperativas, associações e ONG's) recebem as produções de muitos pequenos produtores e as exportam, conjuntamente com sua própria produção, quando também produzem.

Os termos contratuais entre as partes produtora e exportadora variam consideravelmente de acordo com o produto ou o agente exportador. Sampaio et al. (2005) constataram, para exportações de frutas no Rio Grande do Norte, diferentes tipos de contratos, de acordo com o produto exportado e, até mesmo para um mesmo produto e mesmos agentes, opções de contratos distintas.

Entre as principais frutas exportadas pelo RN, três produtos (melão, castanha de caju e manga) têm um ou mais tipos de contratos entre produtores e agentes exportadores. O melão é exportado por uma empresa líder e por uma associação de produtores. A manga é exportada, exclusivamente, por uma empresa (também produtora), que estabelece acordos com os produtores organizados em uma associação. A castanha, quarto produto mais importante, em valor, da pauta de exportações do estado, ficando logo atrás das exportações de melões frescos, 
882 - Modelo Principal-Agente para contratos entre pequenos produtores e empresa exportadora de manga no Rio Grande do Norte

é exportada por grandes empresas e também por uma cooperativa de pequenos produtores (auxiliada por uma ONG).

No Nordeste, é comum o exportador oferecer contratos aos produtores que incluem assistência técnica, administrativa e jurídica; insumos a preços fixos; e recomendações durante o processo produtivo. Esta política permite aos produtores suprir a falta de crédito, tendo acesso aos insumos necessários sem necessidade de capital financeiro elevado para os custos de produção, destacando-se os fertilizantes, as sementes e as embalagens. Assim, a empresa exportadora financia o produtor e ao final faz um acordo de venda consignada do produto (exporta e após recebimento do importador faz o pagamento ao produtor de acordo com o preço de venda correspondente, cobrando um percentual pela comercialização).

O objetivo deste trabalho é a formulação de uma proposta de modelagem, usando a teoria dos jogos, mais especificamente a abordagem Principal-Agente, para os contratos de exportação entre produtores e exportadores da fruticultura. Como objetivo específico, pretende-se aplicar a abordagem proposta para os pequenos produtores de manga do Rio Grande do Norte, avaliando o comportamento das partes envolvidas no contrato e ainda possíveis mudanças contratuais no longo prazo.

Além desta introdução, o artigo inclui, na seção 2, a apresentação do modelo Principal-Agente e em seguida, na seção 3, sua adequação aos contratos de exportação entre produtores e exportadores da fruticultura, com ênfase para a região Nordeste. Na seção 4, mostra-se uma aplicação do modelo para os contratos firmados entre pequenos produtores de manga e empresa exportadora do Rio Grande do Norte. Por fim, a seção 5 traz os resultados e conclusões para a aplicação vista em 4 e algumas considerações gerais sobre a proposta do modelo para problemas semelhantes.

\section{Metodologia}

O modelo Principal-Agente pode ser usado para análise de problemas com informação assimétrica. O Principal contrata um Agente para realizar uma tarefa e o Agente dispõe de uma vantagem de informação sobre seu tipo, suas ações ou o ambiente que os cerca em algum ponto do jogo. Entre as categorias de modelos com informação assimétrica 
estão os de Moral Hazard com ações encobertas (hidden actions) e os de informações encobertas (hidden information ou hidden knowledge) que têm em comum o fato das duas partes iniciarem o jogo, e acertarem um acordo, com informação simétrica, com a assimetria de informação apresentando-se posteriormente (Rasmusen, 1996).

Em geral, um problema Principal-Agente caracteriza-se por um Principal induzindo (através de um contrato) um Agente a realizar certas ações. O Principal pode não estar disponível para observar diretamente a ação do Agente, mas observa algum resultado que é determinado, ao menos em parte, pela ação do Agente. O problema do Principal é designar, no contrato, uma "forma de pagamento" que incentive o Agente a agir da melhor forma possível do ponto de vista do Principal (Mas-Colell, 1995).

O Principal quer escolher uma função s(.) que maximize sua utilidade, sujeita às restrições impostas pelo comportamento otimizador do Agente. Há tipicamente dois tipos de restrições envolvendo o Agente: a primeira representa a sua decisão de aceitar ou não o contrato proposto pelo Principal, analisando outras oportunidades de trabalho disponíveis que lhe ofereçam certa utilidade, um nível de utilidade de reserva, e assim, o contrato proposto deve pelo menos satisfazer esse nível. Essa restrição é assim dita: Restrição de Participação (RP), também chamada de Restrição de Racionalidade do Indivíduo. A segunda restrição é a de Compatibilidade de Incentivo (RCI), em que o Principal deve propor um esquema de pagamento capaz de induzir o Agente a escolher agir como ele deseja (Varian, 1999).

A formulação geral do problema Principal-Agente (baseada em Kreps, 1990) para dois jogadores, um Principal e um Agente, considera: A = conjunto de ações do Agente; $\mathrm{S}=$ conjunto dos possíveis resultados. $\mathrm{O}$ Agente toma ações "a” pertencentes ao conjunto $A=\left\{a_{1}, a_{2}, \ldots, a_{N}\right\}$, onde cada ação "a" produz um resultado " $\mathrm{s}$ " pertencente a $\mathrm{S}=\left\{\mathrm{s}_{1}, \mathrm{~s}_{2}, \ldots\right.$, $\left.\mathrm{s}_{\mathrm{M}}\right\}$, o qual ocorre com uma determinada probabilidade correspondente: $\pi_{\mathrm{n} 1}, \pi_{\mathrm{n} 2}, \ldots, \pi_{\mathrm{nM}}$, tal que $\sum^{M} \pi_{n m}=1$. Assim, para cada ação "a” pertencente ao conjunto A, tem-se uma distribuição de probabilidade $\Pi_{\mathrm{A}}$ em S. Se w é o valor pago pelo serviço, assume-se que o contrato oferecido é uma função $w: S \rightarrow R$. Isto é, se "s" é observado, o principal paga w(s) ao Agente.

Para o Principal, um par de "a" e "s" resulta numa renda $B(a, s)$ e conseqüentemente, os lucros do Principal são dados por: $B(a, s)-w(s)$.

RER, Rio de Janeiro, vol. 45, no 04, p. 879-898, out/dez 2007 - Impressa em novembro 2007 
Modelo Principal-Agente para contratos entre pequenos produtores e empresa exportadora de manga no Rio Grande do Norte

Considerando as probabilidades de resultado diferentes a partir de uma ação $a_{n}$, escolhida pelo Agente, então, os lucros esperados do Principal podem ser escritos como:

$$
\text { Lucros esperados }=\sum_{m=1}^{M} \pi_{n m}\left(B\left(a_{n}, s_{m}\right)-w\left(s_{m}\right)\right)
$$

Para o Agente, supõe-se uma função utilidade de Von NeumannMorgenstern, $\mathrm{u}(\mathrm{w}, \mathrm{a})$, usualmente com $\mathrm{u}_{\mathrm{w}}{ }^{\prime}>0$ e $\mathrm{u}_{\mathrm{a}}{ }^{\prime}<0$. Considerando que cada agente tem outras alternativas, além de trabalhar para o Principal, ou seja, o Agente tem alternativas (externas) que lhe fornecem sua utilidade reserva, ele aceita um contrato proposto pelo Principal se a inequação abaixo verifica-se:

$$
\underset{n}{\operatorname{Max} U t i l i d a d e} \text { esperada }=\sum_{m=1}^{M} \pi_{n m} u\left(w\left(s_{m}\right), a_{n}\right) \geq \bar{u}
$$

Ou seja, a Restrição de Participação (RP) é satisfeita quando a utilidade esperada da ação escolhida $\left(\mathrm{a}_{\mathrm{n}}\right)$ é maior ou igual a utilidade esperada das demais ações disponíveis.

Além disso, o Agente é induzido pelo Principal a tomar a ação que maximiza seus lucros esperados, satisfazendo a Restrição de Compatibilidade de Incentivos (RCI). Para a ação escolhida $\mathrm{a}_{\mathrm{n}}$ :

$$
\sum_{m=1}^{M} \pi_{n m} u\left(w\left(s_{m}\right)-d\left(a_{n}\right) \geq \sum_{m=1}^{M} \pi_{n^{\prime} m} u\left(w\left(s_{m}\right)-d\left(a_{n^{\prime}}\right) \quad \text { onde }: n^{\prime}=1 \ldots N\right.\right.
$$

Desta forma, para cada $w$ e cada ação $a_{n}$ : tem-se um payoff (par de resultados para o Principal e Agente, respectivamente) de:

$$
\sum_{m=1}^{M} \pi_{n m}\left[\left(B\left(a_{n}, s_{m}\right)-w\left(s_{m}\right)\right)\right] ; \quad \sum_{m=1}^{M} \pi_{n m} u\left(w\left(s_{m}\right)\right)-d\left(a_{n}\right)
$$

A Figura 1 mostra como se pode obter a solução deste jogo através de equilíbrio em Subjogo Perfeito, ou seja, resolvendo o jogo de trás para frente. No ultimo estágio, o Agente escolhe sua ação $a_{n}$, de forma a respeitar a RCI; em seguida observa-se se sua utilidade é maior que sua utilidade esperada (RP); por fim, analisa-se que contrato o Principal propõe [o par w(s) e s] dadas as escolhas do Agente, de forma que o lucro do Principal seja maximizado.

RER, Rio de Janeiro, vol. 45, no 04, p. 879-898, out/dez 2007 - Impressa em novembro 2007 
Figura 1 - Forma geral de um jogo Principal - Agente

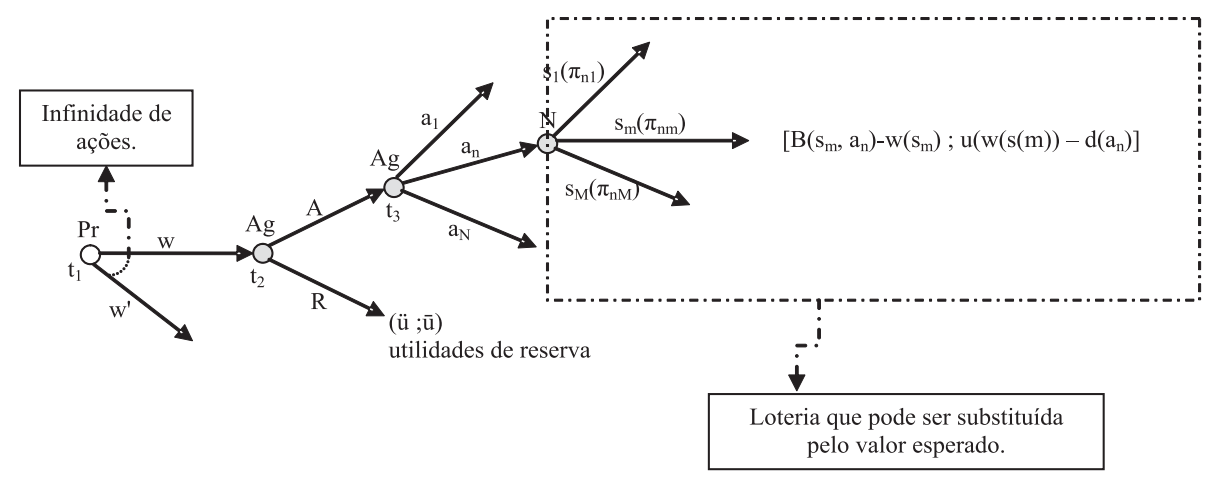

Fonte: a partir da formulação do problema de Kreps, 1990.

Pode-se ter o Principal agindo como monopolista e oferecendo um conjunto de alternativas de pagamento que o Agente irá aceitar se sua expectativa superar seu nível de reserva. Neste caso, determinam-se as propriedades do esquema de incentivos que é ótimo do ponto de vista do Principal. Numa segunda abordagem, há vários competidores Principais, cada um oferecendo um conjunto de esquemas de incentivo, sendo necessário determinar as propriedades dos sistemas de equilíbrio.

Uma diferença básica entre os dois é que no caso do Monopolista, o nível de utilidade do Agente é exógeno e é, tipicamente, a utilidade associada a alguma atividade não relatada. Já no problema competitivo, o nível de reserva é endógeno: este será a utilidade associada aos contratos ofertados pelos demais Principais. Assim, no mercado Monopolista, o lucro máximo será função objetivo do problema e no competitivo, tem-se a condição de lucro zero no equilíbrio.

Supondo um Monopólio com informação completa, ou seja, o Principal tem informação completa sobre as ações e custos do agente e seu objetivo é simplesmente determinar que ações ele quer que o Agente escolha, então seu problema consiste em designar um esquema de pagamento incentivando o Agente a escolher a ação desejada por ele.

A dificuldade nesses esquemas de incentivos é que eles são muito sensíveis a pequenas imperfeições de informação. Se o Agente só recebe quando atingir o resultado estipulado, por exemplo, então sua utilidade esperada pode ser menor que seu nível de reserva de utilidade e ele pode-

RER, Rio de Janeiro, vol. 45, no 04, p. 879-898, out/dez 2007 - Impressa em novembro 2007 
ria recusar-se a participar. Este tipo de problema é conhecido como Problema de incentivo de Ações Encobertas (hidden action problem), já que as ações dos Agentes não são perfeitamente observáveis pelo Principal.

O segundo tipo de imperfeição de informação é quando o Principal não pode observar perfeitamente a função objetivo do Agente. Pode haver vários tipos diferentes de Agentes com diferentes funções utilidade ou funções custos. O Principal deve designar um esquema de incentivo que será bom na média, independente do tipo do Agente envolvido. Esse tipo de problema de incentivo é conhecido como Problema de Informação Encoberta (hidden information problem).

Rasmusen (1996) indicou que os modelos de Moral Hazard, acima, são jogos de informação completa, mas com incerteza. O Principal conhece o Agente, em geral conhece seus custos, e lhe propõe um contrato. O Agente pode rejeitá-lo ou aceitá-lo, e neste último caso, a Natureza adiciona incerteza ao resultado do jogo. Em Moral Hazard, com ações encobertas, o Agente se movimenta antes da Natureza e no caso de informações encobertas, faz suas escolhas após a Natureza, em geral, informando ao Principal algo sobre o comportamento da mesma.

\section{Resultados e discussão}

\subsection{Proposta de modelagem para contratos entre produtores e exportadores da fruticultura}

Nos contratos para exportação na fruticultura nordestina, se o produtor é visto como Principal que contrata um Agente para fazer a comercialização, então pode-se ter um problema de Informação encoberta; o Agente exportador tem mais informação que o produtor sobre o mercado e o preço de exportação.

Entretanto, se o produtor é visto como contratado (como Agente) pela empresa exportadora (Principal) para produzir (como um gerente da produção agrícola), entregando a produção para a empresa que faz a exportação então pode-se ter um problema P-A com ações encobertas.

Propõe-se aqui que os contratos entre pequenos produtores e agentes exportadores podem ser enquadrados em problemas Principal-Agente tendo o exportador como Principal, contratando um Agente para gerir a produção. 
Esta hipótese é sustentada pela observação de que os contatos feitos pelas empresas exportadoras com produtores envolvem, como dito, o fornecimento de insumos e assistência técnica, além da fiscalização do processo produtivo pela empresa, e ao final, controle de qualidade do produto.

Apesar da fiscalização da produção pela empresa com visitas regulares e recomendações sobre usos de insumos etc, a produção não é acompanhada todo o tempo pela empresa exportadora, sendo as ações do pequeno produtor "encobertas", e cabendo a ele decidir se segue ou não as recomendações da empresa.

Em resumo, indica-se que o problema Principal-Agente tem a empresa exportadora como Principal, contratando o pequeno produtor para produzir e este tem ações encobertas, uma vez que ele não é acompanhado todo o tempo pela empresa exportadora.

Com objetivos diferentes dentro do sistema do principal agente, o problema para o esquema contratual restringe-se ao sistema de recompensa que o agente exportador propõe ao produtor. $\mathrm{O}$ exportador (o Principal) tem interesse em maximizar seus lucros que dependem do empenho aplicado pelo produtor no processo produtivo, além de depender de fatores aleatórios (estados da natureza) tais como o regime de chuvas, controle de pragas etc. Apesar do monitoramento da produção, o exportador não dispõe de informação completa sobre o produtor e sobre seus níveis de esforço e, conseqüentemente, os resultados (a quantidade produzida com qualidade para exportação) dependem do esforço do produtor e dos estados da natureza.

As ações do agente (produtor) correspondem à escolha do nível de esforço, compreendendo todo um espectro de ações - esforços. Propõem-se que estes esforços estejam ligados ao percentual da produção que o produtor consegue exportar, ou seja, quanto maior o esforço escolhido pelo produtor maior a quantidade de produto que ele obtém com qualidade requerida pelo consumidor estrangeiro (averiguada pelo agente exportador). O menor nível de esforço reflete o mínimo controle da produção, com o produtor negligenciando as recomendações de produção indicadas pela empresa exportadora e assim obtendo um produto sem qualidade para exportar, podendo ser vendido apenas no mercado interno.

A outra consideração proposta trata dos estados da natureza, os quais indicam se o produtor tem "sorte" ou "não tem sorte" em uma determi-

RER, Rio de Janeiro, vol. 45, no 04, p. 879-898, out/dez 2007 - Impressa em novembro 2007 
nada safra e que têm probabilidades de ocorrer. Sugere-se que a obtenção do valor esperado para os "payoffs" do agente e do principal, no final do jogo, seja feita através de percentuais da produção que podem ser aproveitados para exportação. Esta hipótese baseia-se em conversas com produtores e agentes exportadores de diversos produtos no Nordeste. Eles indicaram que, com "sorte", quando não ocorrem chuvas em excesso ou as lavouras são atacadas por pragas e doenças, é comum que um maior percentual da produção seja aproveitado para exportação. Em resumo, cada estado da natureza está associado a uma probabilidade e corresponde a um percentual de aproveitamento da produção para exportação.

\subsection{Aplicação: contratos entre produtores e exportador de manga no Rio Grande do Norte}

No levantamento dos produtores, disponibilizado pela Associação dos Produtores de Manga Irrigada do Rio Grande do Norte (ASPRON), com dados de 2002 e 2003, constam 34 produtores, dos quais 28 tiveram área plantada, em 2003. Mas apenas 17 já obtiveram produção neste mesmo ano. Verificou-se a expansão da área plantada e da produção que passaram de 279 hectares correspondentes a 2.029 toneladas, em 2002 para 529,5 hectares e 5.736 toneladas, em 2003. Do total de 28 produtores com área plantada em 2003, 16 foram identificados como sócios da ASPRON. De acordo com a localização, há uma concentração dos produtores no pólo Açu-Mossoró: nove em Açu, oito em Ipanguaçu, dois em Carnaubais, e um em cada um dos municípios de Ipanema e Alto do Rodrigues.

A Tabela 1 mostra um resumo dos produtores de manga irrigada, do Rio Grande do Norte, de acordo com a área de produção. Evidencia-se o grande número de pequenos produtores, principalmente com menos de 10 hectares, quase metade do número total. Somadas as duas categorias seguintes, contabilizando assim os produtores de 10 a 40 ha, tem-se número inferior que a primeira categoria. Acima de 40 ha foram identificados 3 produtores: um grande produtor que tem 5 áreas distintas de produção as quais somam 128 ha; a empresa exportadora com 120 ha, em 2003, mas que indicou a ampliação para 200 ha, em 2004, dos quais 142 produzindo; e um produtor com área de 47 hectares. 
Tabela 1 - Número de produtores por tipo, de acordo com a área plantada em 2003, no Estado do Rio Grande do Norte.

\begin{tabular}{l|c}
\hline \multicolumn{1}{c|}{ Faixa da área plantada } & Número de produtores do RN \\
\hline Até 10 ha & 13 \\
De 10 a 20 ha & 7 \\
De 20 a 40 ha & 5 \\
Acima de 40 ha & 3 \\
\hline Total & 28 \\
\hline
\end{tabular}

Fonte: Sampaio et al. (2005).

A empresa exporta sua própria produção e a produção de 26 produtores da região, todos participantes da Associação. O sistema de cooperação (o contrato) mais comum, de venda consignada, entre a empresa e os 26 produtores da região funciona da seguinte forma: ela fornece assistência técnica para esses produtores, numa média de três vezes por safra, correspondendo a: 1) aplicação de reguladores de crescimento; 2) processo de indução floral; e 3) colheita. A empresa ainda determina a dosagem a ser usada pelos produtores, recomenda a poda, a adubação etc. Esse acompanhamento visa um manejo de maior qualidade dos produtores, garantindo a qualidade da manga entregue.

As análises de solo e folha são feitas no IBRA-SP. Antes da colheita, a empresa promove uma avaliação fito-sanitária, observando o produto para verificação das exigências dos importadores (UE e EUA). Ainda, de 10 a 15 dias antes da colheita, é feita uma análise de qualidade, fisiológica, mecânica etc. As amostras são enviadas para o ITEP (Recife) para análise de resíduo. É feito um tratamento pós-colheita para análise de qualidade. Da embalagem até as vendas decorrem cerca de 21 dias, tendo o produto passado pela lavagem, embalagem, resfriamento e colocação em contêiner. Quando o acordo entre empresa e produtor é apenas de compra do produto, venda direta, sem fornecimento de assistência técnica e insumos, a empresa realiza apenas a análise da qualidade do produto final.

A empresa tem o certificado da EuropGap de boas práticas e qualidade do produto, necessário para exportação para a Europa (o processo de certificação foi feito pela empresa paulista SKALL) e ainda está em processo de certificação, pela SKALL-SP, para obter o certificado HACCP exigido pelo mercado americano e também está em processo de certificação 
890 - Modelo Principal-Agente para contratos entre pequenos produtores e empresa exportadora de manga no Rio Grande do Norte

para obter o PIF - produção integrada de frutas - pela Embrapa-Petrolina. Assim, todos esses certificados exigidos constituem em uma barreira à entrada no mercado exportador, e no caso do Rio Grande do Norte, vêm efetivamente colaborando para o monopólio exportador atual.

No sistema de produção para exportação, seguindo todas as etapas de testes descritas acima, o custo médio de produção tanto da empresa como dos produtores é de $\mathrm{R} \$ 7.000,00$ a $\mathrm{R} \$$ 8.000,00 por hectare, obtendo-se uma produtividade média de $20 \mathrm{t} /$ ha. O percentual de aproveitamento para exportação varia de $70 \%$ a $85 \%$ da produção, sendo os demais $30 \%$ a $15 \%$ o percentual de refugo, destinado ao mercado interno. O percentual de "refugo" depende essencialmente do volume de chuvas, surgimento de pragas e doenças (também das condições das rodovias, responsáveis pelos danos mecânicos), ou seja, depende da sorte do produtor que faz acordo de exportação com a empresa.

Dentre os componentes dos custos, os insumos são responsáveis por quase $90 \%$ dos custos do primeiro ano, com maior peso para os fertilizantes e defensivos. Já no sexto ano, os custos com insumos caem para cerca de $75 \%$ dos custos totais, mas aumentam a importância dos gastos com fertilizantes e defensivos. A partir do quarto ano, a receita anual supera a despesa anual, mas apenas no sexto ano ela é suficiente para compensar os investimentos acumulados e assim gerar retorno positivo.

A manga exportada pelo $\mathrm{RN}$, que consiste exatamente na manga exportada pela empresa exportadora, tem como destinos a UE e os EUA, numa proporção de $50 \%$ para cada destino. Nos meses de agosto a outubro, as vendas para os EUA e para a UE são muito dependentes das vendas de Petrolina que, com seus 21.000 há, determina o preço do mercado exportador nessa época. As vendas para a UE seguem ainda de novembro a abril.

Para os EUA, são obtidos os melhores preços em fevereiro e março, quando só o RN está produzindo, no Brasil. Mas destaca-se que é no período de outubro a dezembro, quando é entressafra no México, que o Brasil não tem concorrentes no mercado mundial (Pimentel, 2000). O pagamento feito pelos importadores europeus, após entrega do produto, principalmente nos portos da Holanda e da Inglaterra, geralmente é realizado em duas etapas: na média, em 15 dias é feito um adiantamento e após 45 dias o pagamento completo.

No último ano foram processadas, no Packing-House, seis mil tonela-

RER, Rio de Janeiro, vol. 45, no 04, p. 879-898, out/dez 2007 - Impressa em novembro 2007 
das de manga, o que equivale a mais ou menos 1,5 milhões de caixas de manga. A capacidade do Paking-House da empresa exportadora está ociosa: pode processar 10.000 toneladas por ano e está processando apenas 6.000. Fica evidente a existência de demanda por exportação, principalmente na época em que o Vale do São Francisco não exporta, e essa capacidade ociosa torna natural a estratégia de expansão da produção adotada pela empresa e pelos produtores que comercializam através dela.

Os preços médios obtidos de outubro de 2004 até (o mês de) julho de 2005 , foram de cerca de U\$ 6 e 6 para a caixa de 4,15 Kg, nos EUA e na UE, respectivamente. Em reais, os preços médios foram da ordem de $\mathrm{R} \$ 18$ e R\$21, para EUA e UE.

O valor pago pela empresa exportadora aos pequenos produtores pelo produto varia de acordo com os tipos de contrato. No acordo mais simples, a compra direta, a empresa paga o preço ditado pelo mercado e que variou de R\$ 0,70 a 0,90/ Kg, em 2004 .

Na venda consignada do produto, que é a alternativa escolhida pela maioria dos produtores, após o recebimento do importador a empresa faz o pagamento ao produtor, de acordo com o preço de venda correspondente, cobrando um percentual para cobrir as despesas de comercialização. Do preço FOB, descontados todos os custos de transporte e portuários, a empresa faz o pagamento aos 26 associados, cobrando uma comissão para realizar a venda para o exterior de $7 \%$ a $14 \%$, dependendo do volume entregue pelo produtor.

Em março de 2005, quando um Euro valia aproximadamente R\$ 3,40, obtinha-se cerca de $\mathrm{R} \$ 15,00$ por caixa como preço de venda CIF, na União Européia. Descontados o frete marítimo, comissão de venda e encargos alfandegários, esse valor caia para cerca de $\mathrm{R} \$ 10,00$ por caixa. Subtraindo as despesas de comercialização no Brasil, como etiquetagem, pallet, frete até o Porto de Natal, documentação e despacho, mão-de-obra etc, o valor ficava próximo a $\mathrm{R} \$ \mathrm{R} \$ 7,70$ por caixa. Descontada a comissão de $13 \%$ da Empresa exportadora, a receita do produtor resultante era de $\mathrm{R} \$ 6,70$ / caixa.

A parte da produção não exportada, o "refugo", é vendida para o mercado interno, para intermediários da região que levam o produto para feiras livres, indústria de polpa de frutas ou ainda para demais regiões do Rio Grande do Norte e do Ceará.

RER, Rio de Janeiro, vol. 45, no 04, p. 879-898, out/dez 2007 - Impressa em novembro 2007 
Os produtores que escolhem vender a produção no mercado interno, para o atacado (CEASAS) e também diretamente para o varejo local e regional, como supermercados, feiras livres etc., obtém pelo produto o preço de mercado local, equivalente ao pago pela empresa exportadora quando o contrato é de venda direta, ou seja, em 2004, de cerca de R\$ 0,80/ kg. Como exemplo, segundo o Boletim de Preço no Atacado (SEAGRI, 2005), os preços da manga Tommy Atkins, nas centrais de abastecimento de São Paulo e Fortaleza, foram, respectivamente, R\$ $1,70 / \mathrm{kg}$ e R $\$ 1,16 / \mathrm{kg}$, em 2004. Descontados os custos de transporte e as margens de comercialização do atacado, o pequeno produtor obtém o valor de mercado.

A Tabela 2 resume as opções de contratos para o pequeno produtor de manga irrigada do Rio Grande do Norte descritas acima.

Tabela 2 - Resumo das possibilidades de ganhos do pequeno produtor na comercialização de manga

\begin{tabular}{|c|c|c|}
\hline \multicolumn{3}{|c|}{ Opções de Contratos para o pequeno produtor: } \\
\hline & Valor recebido & Observação \\
\hline 1) Com a empresa: & & \\
\hline Preço Fixo: & $\mathrm{R} \$ 0,80 / \mathrm{kg}$ & $\begin{array}{l}\text { Preço de mercado em 2004/2005, mas que } \\
\text { varia de } R \$ 0,60 \text { a } R \$ 1,40 / \mathrm{kg}\end{array}$ \\
\hline $\begin{array}{l}\text { Venda } \\
\text { Consignada: }\end{array}$ & $\mathrm{R} \$ 1,61 / \mathrm{kg}$ & $\begin{array}{l}\text { Valor recebido pelo produtor: } \mathrm{R} \$ 15,00 / \text { caixa } \\
\text { (Pcif na EU) - R\$ 5,00/ caixa (frete, comissão, } \\
\text { etc.) - R\$ 2,70/ caixa (comercialização no } \\
\text { Brasil) - R \$ 1,00/ caixa (comissão de } 13 \% \text { da } \\
\text { empresa exportadora) = R\$ 6,70/ caixa de }\end{array}$ \\
\hline $\begin{array}{l}\text { 2) No mercado } \\
\text { interno (atacado) }\end{array}$ & $\mathrm{R} \$ 0,80 / \mathrm{kg}$ & $\begin{array}{l}\text { Preço de mercado, calculado como o preço de } \\
\text { venda na Central de Abastecimento de Fortale- } \\
\text { za da manga proveniente do RN, do qual deve } \\
\text { ser descontado o frete Mossoró-Fortaleza e as } \\
\text { margens de comercialização do atacado. }\end{array}$ \\
\hline
\end{tabular}

Fonte: elaboração própria.

Com objetivos diferentes dentro do sistema do principal agente, o problema para o esquema contratual restringe-se ao sistema de recompensa que a empresa exportadora propõe aos produtores (no caso, os dois esque- 
mas vistos). O exportador de manga (o Principal) tem interesse em maximizar seus lucros que dependem do empenho aplicado pelos produtores no processo produtivo, além de depender de fatores aleatórios (estados da natureza) tais como o regime de chuvas, controle de pragas etc. Apesar do monitoramento da produção, o exportador não dispõe de informação completa sobre os produtores e, assim, sobre seus níveis de esforço e consequentemente os resultados (a quantidade produzida com qualidade para exportação) dependem do esforço do produtor e dos estados da natureza.

Uma hipótese simplificadora é estabelecer dois níveis de esforço: o produtor pode escolher entre empregar alto ou baixo esforço. Uma menor dedicação pode ser vista como garantindo-lhe a faixa de preço do mercado interno, uma vez que, provavelmente, se ele não se esforça no controle da produção, seguindo todas as etapas indicadas pela empresa exportadora, seu produto não poderá ser exportado. Assim, baixo esforço garante-lhe receita líquida por kg de $\mathrm{R} \$ 0,60$ a $\mathrm{R} \$ 1,40$, que vai depender dos estados da natureza, ou seja se o produtor tem "sorte" ou não tem sorte” naquela safra. Admitindo ainda que não há possibilidade intermediária e que o produtor ganha, com iguais probabilidades, os valores mínimo e máximo de mercado na região, e que podem ocorrer dependendo dos fatores aleatórios, o valor esperado desses extremos é de R $\$ 1,00$. Em resumo, os ganhos de $\mathrm{R} \$ 1,40$ e $\mathrm{R} \$ 0,60$ foram associados aos resultados obtidos pelo produtor (receitas) para dois estados da natureza, de ter "sorte" ou "não ter sorte", respectivamente, quando ele não se esforça.

Essa primeira hipótese garante que o produtor tem o mesmo resultado entre escolher o contrato de preço fixo proposto pela empresa ou vender no mercado local a intermediários, o que implica na satisfação da Restrição de Participação do produtor diante do contrato de exportação da empresa que lhe leva a seu nível de reserva.

Quando o produtor escolher que vai aplicar um esforço alto (maior empenho e ao mesmo tempo aceita todo o processo de assistência e fiscalização da empresa exportadora), podendo obter com maior probabilidade um produto de maior qualidade, ele tem a opção de exportar seu produto optando pelo contrato de venda consignada. Dado que ele aceitou o contrato de venda consignada, seu esforço garante um produto de qualidade para exportação. Contudo, a quantidade de manga apta para exportar também vai depender dos dois estados da natureza

RER, Rio de Janeiro, vol. 45, no 04, p. 879-898, out/dez 2007 - Impressa em novembro 2007 
894 - Modelo Principal-Agente para contratos entre pequenos produtores e empresa exportadora de manga no Rio Grande do Norte

considerados aqui - "sorte" e "má sorte”. A maneira como estes estados afetam a qualidade da manga para exportação é, por hipótese, associada à taxa de "refugo" indicada pela empresa exportadora. Se o produtor tiver "sorte" ele pode obter, por exemplo, R\$ 1,61/ kg sobre $85 \%$ da produção, considerando $15 \%$ como uma taxa de refugo baixa e observada para os produtores mais produtivos da região; ou pode perder até $30 \%$ da produção no caso de "má sorte” e obter R\$1,61 sobre $70 \%$ da produção. O que interessa é a diferença entre os percentuais de refugo para o estado da natureza de sorte e de má sorte, aqui estipulada em $15 \%$.

A Figura 2 exemplifica as opções de contratos descritas acima, para um pequeno produtor, com 10 hectares (área do maior número de produtores associados), como Agente e a empresa exportadora, como Principal Monopolista, para o ano de 2005. Se o Agente (pequeno produtor) aceita o contrato de venda consignada e aplica alto esforço (ação a na figura), considera-se o aproveitamento de $85 \%$ da manga para exportação (refugo de $15 \%$ ), com uma produtividade de 20 t/ha, resultando em produtividade aproveitada de $17 \mathrm{t} / \mathrm{ha}$, ou seja, produção de 17.000 $\mathrm{kg} /$ ha, cuja receita recebida será de $\mathrm{R} \$ 1,61 / \mathrm{kg}$, totalizando $\mathrm{R} \$ 27.370$ /ha. Subtraindo um custo de R 8.000 por hectare, seu lucro esperado contábil por hectare será de $\mathrm{R} \$ 19.370$, e assim, para 10 hectares seu lucro esperado contábil será de R\$ 190.370/ ano. Seguindo o mesmo raciocínio, se o produtor aplica baixo esforço e assim passa a obter um aproveitamento de $70 \%$ da produção (refugo de 30\%) com a mesma produtividade de 20 t/ha, seu lucro esperado contábil é de R 145.400 / ano. Caso o produtor não aceite o contrato de venda consignada da empresa, ele vende toda a produção de 10 hectares (sem percentual de refugo), com produtividade de $20 \mathrm{t} / \mathrm{ha}$, ao preço de $\mathrm{R} \$ 0,80 / \mathrm{kg}$, no mercado local para um intermediário ou para a própria empresa exportadora, mas sem acordo prévio. Assim, o produtor tem receita anual de $\mathrm{R} \$ 160.000$ e custos de $\mathrm{R} \$ 80.000$ (mesmo custo de oito mil reais por hectare), resultando no lucro contábil de $\mathrm{R} \$ 80.000$ por ano.

Se o Agente aceita o contrato, o Principal obtém lucro contábil anual de $\mathrm{R} \$ 33.600$ ou de $\mathrm{R} \$ 40.080$ para baixo ou alto esforço do produtor, respectivamente. A diferença corresponde ao percentual sobre a comercialização que é deixado de ser vendido quando o produtor aplica baixo esforço e sua produção é menor. Caso o Agente não aceite o contrato, 
a empresa exportadora não tem perdas diretas, mas arca com o custo de oportunidade de ociosidade de seu packing-house, podendo este ser considerado o nível de utilidade reserva do Principal.

Figura 2 - Exemplo de Jogo Principal - Agente envolvendo a empresa exportadora monopolista e um pequeno produtor de 10 hectares de manga

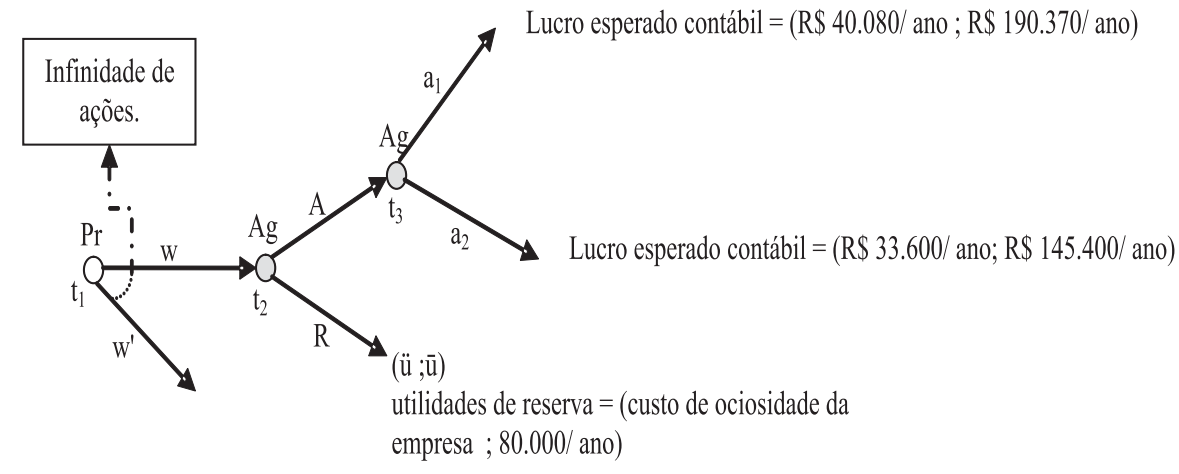

Fonte: elaboração própria, à partir da Figura 1

Como dito na metodologia, a solução pode ser encontrada através de equilíbrio em Subjogo Perfeito: resolvendo de trás para frente (os subjogos). Substituindo a última loteria da Figura 1, correspondente aos possíveis estados da natureza, por seus valores esperados, passa-se para o nó $t_{3}$, no qual o Agente escolhe entre as duas possíveis ações: alto ou baixo esforço. Em $\mathrm{t}_{3}$, o Agente vai escolher alto esforço se a utilidade esperada desta ação for maior ou igual à utilidade esperada de aplicar baixo esforço.

Observando os lucros, o Agente escolhe $\mathrm{a}_{1}$ - aplicar alto esforço caso ele atribua a seu esforço valor menor ou igual à diferença entre os lucros de se esforçar ou não, no caso diferença de R\$ 190.370 - R\$ $145.400=44.970 /$ ano, ou algo como R\$3.747,50 por mês. Supondo que sim, o Agente passa para $t_{2}$.

A utilidade esperada da ação escolhida $\left(\mathrm{a}_{1}\right)$ tem que ser maior ou igual à utilidade esperada das demais opções disponíveis (RP), ou seja, o nível de utilidade reserva para o produtor. Caso o Agente rejeite o contrato de venda consignada, ele tem a opção de vender, a preço de mercado, para a empresa exportadora ou no próprio mercado. Em ambos os casos, o pro- 
896 - Modelo Principal-Agente para contratos entre pequenos produtores e empresa exportadora de manga no Rio Grande do Norte

dutor obteria lucro contábil de 80.000/ ano, considerando produtividade de 20 t/ha e preço de mercado da época do levantamento de R\$ 0,80/ kg. Assim, em $t_{2}$, o Agente aceita o contrato proposto pela empresa.

Em $t_{1}$, o Principal escolhe $w(s)$, s pertencente a $\mathrm{S}$, dadas as escolhas do Agente em $t_{2}$ e $t_{3}$, tal que o payoff (lucro esperado) do Principal é maximizado. Ou seja, no início do jogo o Principal (empresa exportadora) decide que contratos oferecer. Para o Principal, o melhor é que o Agente aplique alto esforço, o que lhe proporciona uma receita de cerca de $\mathrm{R} \$ 40.000$ por ano de cada pequeno produtor de 10 ha. Oferecer o contrato é vantajoso para a empresa se a sua receita com a comercialização for superior aos seus custos com a exportação. Como a empresa está atualmente com seu packing-house ocioso, supõe-se que os custos de ociosidade são muito superiores aos custos de processar a produção dos produtores associados no packing-house.

\section{Conclusões}

A modelagem dos contratos entre produtores e agentes exportadores pela abordagem Principal-Agente mostrou-se adequada para avaliar os comportamentos de ambas as partes e permitir uma análise estratégica para as mesmas.

Para a aplicação realizada, em resumo, observou-se que o contrato, proposto pelo Principal, incentiva o Agente a aplicar alto esforço e a maximizar a utilidade (os lucros) de ambos os participantes no acordo. O caso descrito foi para um pequeno produtor de 10 hectares, e considerando dois possíveis estados da natureza. Contudo, a aplicação para qualquer tamanho de área estabelecida é similar. De modo geral, considerando que a rejeição do contrato pelo produtor é equivalente a vender a produção à empresa ao preço de mercado, a decisão do produtor entre aceitar ou não o contrato depende dos seus lucros esperados para seus níveis de esforço e da sua utilidade reserva. Na situação atual, aceitar o contrato, independente do nível de esforço, é ótimo para o produtor, justificando as ações de todos os associados da região.

Dado que o produtor resolve aceitar o contrato de venda consignada, ele decidirá se é vantajoso aplicar alto esforço ao invés de baixo esforço se ele atribui à diferença entre ambas as opções uma utilidade maior 
que a utilidade negativa de aplicar o maior esforço. Para a aplicação, os retornos de alto esforço são até $30 \%$ superiores aos de baixo esforço.

A empresa exportadora pode oferecer infinitas possibilidades de contrato, ou seja, cobrar diferentes percentuais de comercialização para diferentes tipos de produtores (tamanho dos mesmos ou qualidade do produto exportado, fazendo o preço variar). Seus contratos, atualmente, devem ser decididos analisando-se suas receitas com a comercialização da produção dos pequenos produtores e seus custos de oportunidade de manter o packing-house ocioso. Como a empresa estava trabalhando com pouco mais da metade de sua capacidade (60\%), seus custos de oportunidade devem ser altos, o que a incentiva a negociar com os produtores associados.

Contudo, a empresa está expandindo sua área de produção rapidamente e, no longo prazo, após a aquisição de área de produção, plantio e espera de seis anos necessários para obter a produtividade de 20 t/ ha, eliminando a restrição de fator fixo de curto prazo, ela pode ser capaz de suprir toda a capacidade de seu packing-house com sua própria produção. Neste caso, os contratos podem ser revistos; o percentual cobrado por ela para comercializar a produção dos pequenos vai ter que ser superior aos seus lucros de exportar sua própria produção. Uma outra possibilidade é a expansão da capacidade de processar (novo packing-house), caso a demanda mundial pelo produto em questão continue crescendo, ou seja, pode-se estudar a viabilidade econômica da construção de novo packing-house.

Outras aplicações envolvendo produtores e exportadores, da fruticultura do Nordeste e do Brasil ou da produção agrícola, em geral, com estruturas de contratos semelhantes, podem ser realizadas, com as devidas adequações. Alguns contratos, por exemplo, entre produtores e exportadores envolvem barganha nas negociações, que pode ser incorporada nos modelos Principal-Agente sem maiores dificuldades. A modelagem proposta para produtores e exportadores permite que os exportadores sejam empresas, ONGs, cooperativas ou associações e em alguns casos mais de um deles. Nestas situações, com vários agentes exportadores, a diferença é uma mudança na utilidade reserva dos produtores. Por fim, pode-se considerar que produtores e exportadores firmam contratos ano após ano, ou seja, pode-se considerar um modelo de jogo dinâmico.

RER, Rio de Janeiro, vol. 45, no 04, p. 879-898, out/dez 2007 - Impressa em novembro 2007 
898 - Modelo Principal-Agente para contratos entre pequenos produtores e empresa exportadora de manga no Rio Grande do Norte

\section{Referências bibliográficas}

KREPS, D. A Course in Microeconomic Theory, Princeton: Princeton University Press, 1990.

LACERDA, M. A. D.; LACERDA, R. D. O Cluster da Fruticultura no Pólo Petrolina-Juazeiro. Revista de Biologia e Ciências da Terra, v.4, n1, 2004.

MAS-COLELL, A.; WHINSTON, M.D.; GREEN, J. Microeconomic Theory, Oxford University Press, New York and Oxford, 1995.

MDIC - Ministério do Desenvolvimento, Indústria e Comércio Exterior. www.desenvolvimento.gov.br, 2006.

PIMENTEL, C.R.M. Oportunidades e Barreiras à Expansão do Comércio Internacional para a Manga Nordestina, Revista Econômica do Nordeste, 31 (2), 10-21, abr/jun, 2000.

SAMPAIO, L. M. B.; SAMPAIO, Y.; GURGEL, A. Estudos de cadeias produtivas das frutas de exportação do Rio Grande do Norte, Mimeo (Relatório para o Sebrae-RN), 2005.

SEAGRI - Secretaria da Agricultura e Pecuária do Estado do Ceará, SIGA (Sistema de Informação Gerencial Agrícola). http://www.seagri.gov.br, 2005.

VARIAN, H. Intermediate Microeconomics: A Modern Approach, New York: IE-WN Norton Press, 1999.

FUDENBERG, D.; TIROLE, J. Game Theory, Cambridge, MIT Press, Massachusetts, 1991.

PAULA PESSOA, P. F. A.; OLIVEIRA, V. H.; SANTOS, F. J. S.; SEMRAU, L. A. S. Análise da Viabilidade Econômica do Cultivo do Cajueiro Irrigado e Sob Sequeiro, Revista Econômica do Nordeste, 31 (2) 178-187, abr/jun, 2000.

RASMUSEN, E. Games and Information, An Introduction to Game Theory, Blackwell Publishers, Cambrige and Oxford, Reino Unido, 1996.

Recebido em outubro de 2006 e revisto em março de 2007.

RER, Rio de Janeiro, vol. 45, no 04, p. 879-898, out/dez 2007 - Impressa em novembro 2007 